\title{
The East as a Theatre House of Suffering: 'Suffering' Scholarship and the Orientalist Bind
}

\author{
Yasmin Ibrahim
}

\section{Introduction}

The scholarship of suffering is in a Eurocentric bind - with the West as the possessor of the humanitarian gaze and the East/Global South as the recipient of this politics of pity (see Boltanski 1999, Hoijer 2004, Chouliaraki 2006). The panacea to eradicate the lack of compassion or pity is the enactment of cosmopolitan communities filled with diversity, so that the suffering "Other" is not a remote fantasy figure but made familiar through this idealized inclusive community. Hence, this Other is us. Suffering can also produce fetishized consumer communities which buy into the solidarity of the moment without engaging with the politics of pity (Chouliaraki 2013). Scholarship on the subject of suffering located through its vantage point of the West consuming the East or the Global South has cast itself into a binary of power relations through the construction of abjection and pity, elongating the tropes of Orientalism. Embracing the idea of suffering through media platforms, media representations and media texts, the notion of "mediated suffering" premises a process of communication (including an emotive and cognitive immersion into a constructed environment but equally a degree of removal) where technology and content reconfigure distance, proximity, morality and notions of humanity in this realm of scholarship. Premising suffering through the media event and not what preceded before or followed after, suffering scholarship retains media spectacle as its vantage point for studying audience compassion for the unknown Other and its victimhood, dictating a "proper distance" (Silverstone 2006) to enable a viable and humanitarian response to the Other in crisis.

The dichotomization of the West and the rest (i.e. read through its alterity) becomes an underpinning paradigm in these discussions without a deconstruction of the trajectory of humanitarian discourses which have originated from unequal power relations and domination. This occurred particularly through colonization, the hegemony of Western power relations and ideology after World War II, the hand of forceful capitalism and neoliberalism in opening up markets under the guise of globalization, and the formation of the Global South as a label of social and economic depravity. The scholarship of suffering hinges its analysis through the act of watching or through the broader ambit of consumption. The consumers become audiences of a screen culture and its attendant subjectivities, mediated both through technological manipulation and the modes of representation. Some of the literature on suffering encodes these audiences as "witnesses" to the events which unfold on the media(ted) stage (see Ibrahim 2010a). Suffering then appropriates a cartography where the theater of suffering is projected onto the East or Global South through the act of watching, through replay, through freeze-frames which catapult suffering into its own representational hegemonies and aesthetic modes in our technological world. The ability to feel compassion and pity, coalesce with a Western geopolitics of power such that the ability to feel pity becomes the resting site of the Western gaze and its sociological imagination of the distant Other as the lesser human, continuously impoverished through her vulnerabilities and suffering. Such an imagination is persistent in the construction of the African continent conceived through famine and genocide, and equally in fiction and popular culture, where the continent is produced 
through a pornography of depravity (see Ibrahim 2018). Humanitarian and aid organizations then project these constantly though their media campaigns, conjoining Africa into monolithic whole enacted through its lack.

In the scholarship of suffering universal human emotions of pity, compassion and sympathy become enacted through the consumption of the Other in turmoil through media imagery and text. Hence, the media and mediated technological platforms provide a filter to assemble these narratives of suffering. The coalescing of the politics of pity with the geopolitics of power creates a spatial cartography which inserts a distinct divide between the consumers of mediated suffering (i.e. as experienced through media formats) and those represented, as they are constantly besieged through perennial diseases, malnutrition, natural disasters, wars, strife and anarchy. This cartography of suffering enables the distant Other to be performed through the pathos of an unfortunate entity - entrapped through this Orientalism and commodified for the West. This also means that the West as the consumer of suffering is only able to feel for the Other through certain genres of suffering, as not all types of suffering can be projected onto mainstream consciousness. Tribal wars between sects or genocides, for example, are less amenable for popular consumption. Where the West is less socialized into these genres of suffering there is less popular appeal in terms of representing it to the masses.

This paper examines the Orientalist predicament of contemporary scholarship on mediated suffering. It argues that mediated suffering needs to be cast within the context of historical power relations of conquest, oppression, colonization and the attendant missionary zeal to civilize the East. It argues that colonization and slavery has historically marked the body of the distant Other as a site of violence and suffering, of possession and dispossession and containing no moral limit to the brutality it endured. The scholarship of suffering has produced binary cartographies of the world through those who consume suffering and those whose suffering is commodified for consumption. Mediated platforms of suffering, particularly photographs and broadcasting, have privileged the eye where the visual becomes the resting site of authenticity and simulated pity and equally the means for the pornographic and perverse imagination of the body of the Other. Hence, beyond the charge of Orientalism, the bias of visuality in the scholarship of suffering prolongs a troubled but pseudo-humanitarian gaze of the Other.

Despite the trenchant Orientalism and visual bias within the realm of the scholarship of suffering, I argue that the axis of suffering has shifted since $9 / 11$ where even the most powerful nations in the West are reframed as victims of suffering and violence unleashed by the Other. With an increasingly volatile world, it has become difficult to retain a static notion of the East and Global South in constant crisis and turmoil. With global warming and its attendant environmental repercussions, and displacement and mobility of people through war and terrorist attacks, the cartography of suffering has been ruptured. The social imaginary of the East as the theatre house of suffering has expanded to accommodate the unstable West. Despite these numerous ruptures, the East remains a spectacle of suffering due to the retardation both in the fields of the scholarship of suffering and the need to retain a beleaguered human form of the Other imagined through strife and disaster. This aesthetic rendition positions vulnerabilities away from the West in the global social imaginary to renew its potency over time.

\section{| Critique of the Scholarship}

The criticisms about contemporary scholarship of suffering (which tends to be cross-disciplinary with its emphasis on mediated forms of suffering) parallel those levied on trauma theory as a field of enquiry which "emerged in the early 1990s as an attempt to construct an ethical response to forms of human suffering and their cultural and artistic representations" (Andermahr 2015: 500). Sonya Andermahr points out that trauma theory "born out of confluence between deconstructive and psychoanalytic criticism and the study of Holocaust literature" sought from the outset to "bear witness to traumatic histories in such a way as to attend to the suffering of the other" (2015: 500). It has however been charged with privileging the trauma of White Europeans rather than being cross-cultural and neglecting the specificity of non-Western people and the trauma of ethnic minorities. Critics have argued that trauma theory's failure to forge a relationship with the non-Western Other, while premising the vantage point of the Western gaze, has led for a lobby to reroute the field (Luckhurst 2008). As such, there has been a resurgent call to release trauma scholarship from a Eurocentric bias and liberate the field from this hermeneutic bubble of Western essentialism (see Craps 2013; Bennet and Kennedy 2003; Rothberg 2008; Luckhurst 2008).

Stef Craps (2013:2) in mounting a critique of Western bias in trauma theory through his book, Postcolonial Witnessing, argues that trauma theory takes on a universal definition of trauma and recovery developed through the 
history of Western modernity and hence marginalizes the traumatic experiences of non-Western cultures. Craps (2013: 31) contends that a major deficit of the field is to construct trauma through a singular "event-based model" which delimits wider historical processes or even the West's role in the predicament of the Other. For Rothberg, "the singular event-based model is distortive for it does not deal with the colonial and postcolonial traumas persisting into the present," and he invites the rethinking of trauma as "collective, spatial, and material (instead of individual, temporal, and linguistic)" (2008: 228). Craps (2013) cites racism as historically specific yet not defined through one event or what follows before or after this paradigmatic event. As such, historically rooted trauma emerging through a global system such as colonization and slavery presents endemic challenges to the Eurocentric models of trauma theory. Depoliticization and de-historicization are also deemed as major obstacles in trauma theory (Visser 2015). The Eurocentric bind of trauma studies is untenable as it distorts history and reproduces the very Eurocentrism that lies behind those processes (Rothberg 2008). As such, it ignited a resounding call amongst its critics to decolonize trauma studies.

The critique of trauma theory is applicable to the scholarship on suffering and equally to media studies as a field which the scholarship of suffering draws on. Media and cultural studies, being interdisciplinary, draw from other fields such as memory and trauma studies and as such can infuse these inherent biases. Despite the expansion and consolidation of media and communication studies in the last thirty years, much of the field is somewhat unaffected by postcolonial paradigms and multicultural norms or value systems. For example, the normative values ascribed to media and its functions in society are often deemed as universal, as such there is a failure to particularize it through the political systems which emerged after World War II, or approach these through postcolonial paradigms. Media studies' endeavor to integrate wider paradigms and cultures have produced a weak and fragmented call to "internationalize" or "de-westernize" rather than to decolonize the field and to integrate the postcolonial (see Ibrahim 2011).

With reference to the scholarship of suffering accruing from the field of media and communication and processes of mediation which tend to privilege second-hand witnessing through media platforms, it is often ahistorical and event-based while using Western definitions of trauma and morality as universal. The premising of media in reviewing suffering equally means there is a need to understand media and power relationships without decoupling them from the postcolonial, historical trajectories or the particularities and specificities presented through minority cultural frameworks. The mining of media text alone without situating it within wider social or historical frameworks reifies media representations as reality onto its own. In terms of research into suffering, it produces a binary cartography and creates a Eurocentrism which is difficult to defend as a vantage point when it in effect distorts history and reality. The call to decolonize research into suffering can then be equally extended to media studies which is sporadic in integrating historicity and the postcolonial in its vantage point.

\section{The Aesthetics of Suffering and the Orientalist Gaze}

In reviewing the criticism of the scholarship of mediated suffering within media and communication studies, its Eurocentric bias elongates the project of Orientalism. While suffering represented through cultural formats is problematic and amenable to multiple iterations, Edward Said additionally illuminates cultural imperialist gaze as an added dimension of this complexity. According to Said (1978), Orientalism examines the ways in which the West imagines the East as the lesser Other. The East is fetishized through a power relationship and equally through perverse pleasures and desires which demarcate the East through a carnal savagery. The Orientalist gaze, pregnant with a relentless and perverse aesthetics of the East as yielding both the exotic and untamed, laid the grounds for the re-conditioning of suffering through this form of commodification as an Orientalist subject.

Said's (1978) concept of "Orientalism" as a critical category surveyed how the West perceived the East through a set of discursive practices. As such alterity could be induced even within the category of Europe. For example, Wolff (1994), drawing on Said, argued that during the Enlightenment Eastern Europe was conceived as the "Other," similar to the West's more recent gaze on the Middle East. As such Todorova's (1997:17) "Balkanism" thesis concurs that the West viewed the Balkans as depraved in terms of humanity and civilization. The West and its "civilization values" have become the undisputed norm, and the relationship between Europe and its "others" is "monitored and regulated through a system of disciplinary discourses and techniques invoking the oriental East as Europe's threatening external" (Haldrup, Koefoed, and Simonsen 2006, 174). This "resurgent Orientalism" is present in 
Europe's relations to its external "others" and in a "growing hostility towards its internal others." As such Orientalism and the process of the creation of Other were contiguous with the modernist condition of the world where neither the fluidity of space nor topography of power have eradicated the mindset of constructing social distinctions and retaining the "Other" (Buchowski 2006: 466).

The East possessed no moral limit with its inherent atavism and propensity to slip back into savagery. This is a crucial point for reviewing the scholarship on suffering. It needs to be critiqued in terms of its East-West hermeneutics, where colonization and ownership of the native by conquering the Other retained its residue in terms of its power to own and possess the Other. The body of the Other is as such inscribed as a site of suffering. The embodied Other is owned and equally dispossessed through colonization, war, strife and slavery. The Orientalist gaze predates mass-mediated suffering where the gaze has enabled the body of the Other to be transgressed and equally recoded as the site of trauma. Suffering was further demarcated through the spatial categories of center, margin and periphery, imposing a further cartography of violence. Within it is an inference that suffering is an attribute of the lesser human, where the powerful is fortunate enough to consume this suffering but not to be identified through it or implicated with it.

In postmodernity, new spaces have emerged as sites containing the victims of modern slavery and coercive labor. The inmates in Guantanamo Bay, the deviant "migrant" in the makeshift camps of Calais, the dispossessed population struggling to deal with the border politics of occupied zones, and the suicidal factory workers relentlessly producing gadgets for insatiable consumers before a product launch. Both the "war on terror" and the neoliberal movement of capital carved out their own geopolitics of suffering, where the playground of violence is enacted in complex ways through a geopolitics of power and the demands of capital. These spaces in postmodernity have become sites of entrenched suffering which co-exist with the mediated suffering of natural (e.g. tsunamis) and man-made disasters (e.g. nuclear explosions). These non-spaces which become the receptacles for coercive forms of labor, confinement and subjugation co-exist with a wider geography and cartography of suffering, where the flow of capital and neoliberal ideologies resurrect an intrinsic logic (whether through the war on terror or to feed the hand of capital) to retain and legitimize the suffering in these non-spaces.

Beyond the aesthetics of suffering which emerged through this geopolitics of power, violence and trauma must also be reviewed in terms of the pull towards the abject in the human psyche and sub-conscience. Violence and suffering as forms of aesthetic consumption illuminate the primal within the human. The pull towards the abject (see Kristeva 1982) and the aestheticization of violence integrates a history of human subjugation and domination. As history has revealed, the sites of suffering have not always produced or yielded pity. Nor do they always perform as transformative devices in enabling pity or compassion for the Other or for the emergence of an enlightened humanity. Artefacts of suffering as envisioned through the dead or damaged body in cultural modes of representation (e.g. the photograph, the lanterna magica, the video) are not always a catalyst for pity or mass communion or for the repudiation of violence. They serve to reiterate power hegemonies and to become the exemplar for the treatment of the Other, lest they overstep the mark. The suffering of the body conjoined with power hegemonies produce a biopolitics, where the body can be constantly surveilled, gazed and castrated. As such, suffering (both its infliction and consumption) through time has operated through an entangled web of power hierarchies and ideologies, which have appropriated complex juridical discourses to legitimate suffering and trauma on the Other.

For example, the history of lynching in America paraded the dead body as a form of social justice, as a violent trophy of instilling honor, ownership and racial superiority. People drove from faraway places to watch the lynched body dangling from a rope. No dignity was offered even in death and the moment of death became prolonged through the violating gaze of the hungry public eager to consume the abject. The dead body functioned as a site of aesthetic violence, drawing large crowds not in the capacity of witnesses but as a spectacle for the legitimation of the violence and for the social order it restored [1] (see Garland 2005). These violent lynchings, though "infrequent and extraordinary, assumed tremendous symbolic power due to [their] public and sensational nature" (Wood 2011:1) It entered aesthetic modes memorialized through postcards and shared with a wider population as cultural artefacts commemorating the euphoria of violence, whilst marking the lynched body as the site for the restoration of order. Here suffering and trauma enacted through White superiority did not enact compassion or pity but encoded the body as a site of deviance and voyeuristic pleasure. The history of violence, suffering and trauma is complex through time and space but the body of the Other is a contested space which is often offered as a site to be consumed by others. Often the gaze is an invitation to read the body of the Other through power hegemonies and prevailing ideologies. Most importantly, the body of the Other is heavily entangled with the historicity and its attendant power economies. Hence, an event-based analysis alone would thwart history and reality, where bigger processes and social conditions 
have produced this theatre of suffering.

\section{Mediated Suffering}

Mediated suffering is mired in various complexities notwithstanding its premising of technological platforms to receive images and narratives of suffering. Suffering mediated through artefacts becomes once removed from the real events and twice removed due to the modes of representation within cultural artefacts. Distant suffering conveyed through imagery such as photographs, prints, moving images or art acquires its own code of aesthetics which strips it from the real, making it amenable to different forms of gaze, infusing pleasure, violence and desire onto the afflicted. While having the potential to ignite pity or mass response from its audience, embodied human suffering is amenable to multiple iterations. It can be imagined through a visuality which premises the eye where the visual bias has the potency to recode sites of suffering, commodifying them as objects for consumption to assuage primal human instincts and voyeurism. Kevin Carter's dying child preyed or by a vulture or the emaciated human forms dying from famine arranged for the aesthetic eye in colonial India inscribe a perverse gaze onto the dying body. It reiterates the dominance of the primal where the human form and its suffering are appropriated to ignite voyeuristic pursuits. Here the human and its suffering are dissolved and subsumed through an aesthetics which realizes pleasure through the wasting forms. Hence, this death figure is transformed through its depiction where its aesthetics recode for visual semantics and pleasure rather than pity.

If Kodak created a visibility into the unboundedness of human suffering of the enslaved body in the Congo of Leopold II - it also recorded the maimed bodies as mythical figures of Western domination, where limbs and torsos dismembered and truncated from the enslaved body dehumanized the Other, casting them into fictional depictions despite the reality of their predicament (see Ibrahim 2009). Beyond the visual bias in representations of suffering, mediated suffering through photojournalism and broadcasting brought suffering into the living room for consumption. The reconfiguration of time and space through the act of watching made images of suffering pervasive and common, filling column inches, scrolling reports and headlines. The consumers of suffering became audiences of these mass spectacles rather than fellow humans of a wider humanity. Broadcasting and the political economy of the media further entrenched and reproduced the spatial cartography of suffering, commodifying the suffering of the East for the West. The exotic and unknown became objects of communal gaze in the broadcasting age. The inundation of suffering and the trauma marathons (Blondheim \& Liebes 2002) have led to claims that the saturation of suffering created "compassion fatigue" among audiences (see Hoijer 2004; Tester 2001).

As such, the representations of suffering can be aestheticized and banalized through pervasive capture and consumption in the age of broadcasting. Digital platforms and the ability to upload and download images enabled new forms of access to suffering, where images of suffering can be watched without the mainstream media's codes of taste, decency or standards. Equally, videos and images of suffering can be consumed without context or media narration, propelling mediated suffering into a crisis of consumption in the digital age (Ibrahim 2010b; 2012). Online platforms provide different types of access and intimacy with content and produce a fragmented audience exposed to a variety of content produced either by mainstream actors or those on the margins. For example, the reporting of beheadings by the print media and television from before the digital age to its revival in the social media age produces a body of gratuitous violence which can be accessed by a wide population. Issues of taste, decency or the ethical standards expected of mainstream media become difficult to uphold and maintain in the online space. This again reconfigures the spectacle of suffering online where it is fragmented and mediated through a whole array of interests and agendas, where images of beheading have become genres of popular culture highlighting the role of the digital platform as enabling new modes of aesthetic violence.

\section{The Shifting of Suffering and New Normality}

Beyond new platforms to upload and consume images and narratives of suffering, there has been a seismic reconfiguration of the cartography of suffering since $9 / 11$. The apocalyptic images and their impact as an iconic media event have repositioned suffering, where the West is the site of the uncertain and the unstable through the 
threat of terrorism arising from the "war on terror," providing it with an intrinsic logic to militarize zones and engage in long drawn-out wars as evident in Afghanistan and the Middle East. The visuality of 9/11 as an iconic media memory played and replayed as a material and symbolic event on media introduced a disruption in the trope of suffering, turning the mirror of suffering onto itself. The projection of victimhood onto its persona was a gamechanging moment for the cartography of suffering. The combustion of the Twin Towers as a recurrent image was also symbolic of the shattering of Western pride (Ibrahim 2007) and its recurrent thrusting of victimhood to the Other in remote locations. It seismically destabilized the West's position as the humanitarian and philanthropic champion looking over the impoverished Global South.

Silke Horstkotte (2013: 37) argues that "the 9/11 attacks derived their shock value to a large extent from the way in which this terrorist atrocity was so clearly 'made for TV."' But it was equally the stuff of the scholarship of suffering fitting neatly within its fixation with the event-model without scrutiny into what came after or before. But unlike other events of pathos, it was a superpower freeze-framed through its destruction and annihilation by the Other. These enduring image archives gave birth to the West as the new project of suffering. The West, imagined through the notion of cities under siege without warning from terrorist attacks and explosions, has become a site of volatility despite enhanced security and intelligence. The events of $9 / 11$ stand in contrast with the mediation of the Holocaust in terms of the public spectacle or its moral censure. The horrors of the Holocaust emerged over a long period of time with liberation images of the camps, televised trials and survivor testimonies. In contrast, 9/11 as a televisual spectacle was instantly accessible and quickly proliferated on screens across the globe. For WJT Mitchell (2011), the new transnational terrorism is largely based on spectacular symbolic acts aimed at the production of images that are meant to shock or even "traumatize" the spectator. The phenomenon of instant coverage was familiar to Western viewers from previous events, such as the fall of the Berlin Wall, but the speed and extent to which images were deployed as weapons was entirely new (Horstkotte 2013: 38). In many ways, research into suffering is interested in this moment of visual ousting, where imagery defines the inexplicable engagement with the trauma spectacle rather than the longer trajectory of working through this trauma and enabling recovery. The media spectacle as such delimits the scholarship of suffering, highlighting the field's double bind with technology and its bias with the visual.

Despite the shifting of the axis of suffering with $9 / 11$ and the events which ensued, the victimhood of the West is constantly resisted by repositioning the enemy as the Eastern Other wreaking disruption through radicalized ideology and violence. The events of $9 / 11$ placed suffering and victimhood into the ambit of the rich and influential Western nations and cities as their symbols of power, and the series of attacks which ensued after 9/11 again reiterated the instability of the postmodern world, where suffering and loss happened not in faraway locales of war and strife but within the ordered and governed cities in the West. As such, the West is now a site for mindless killings and brutal attacks on innocent people. Unlike natural disasters, the terrorist attacks and the notion of constantly being under terrorist threat through the atavistic Other have infused a sustained anxiety in the West where this instability of cities exploding without warning signified the "new normal."

Beyond terrorism, the displacement of people through conflict and terror has witnessed the significant movement of people fleeing from war and strife, bringing them into the border politics of the West. This movement of people into the borders of "Fortress Europe" raises a renewed crisis in terms of suffering. The refugee branded the "migrant" in neo-liberal politics is a contested figure or a suspect category where incessant doubt is invoked about affording this figure any pity or compassion once positioned in the West, having fled their homelands in the East. The encroachment of alien bodies into the West fragments the politics of suffering, where the West is constantly under terrorist attacks and increasingly its borders are infiltrated by the movement of unwanted migrants and refugees posing risks and unforeseen dangers to Fortress Europe and other Western nations. As Amitav Ghosh (1994:422) observes,

we are witnessing a fundamental shift in the political institutions of the century with the emergence of a two-tier system of nation states. On the one hand, the boundaries of the nation-state will become increasingly blurred and on other, those boundaries will become increasingly entrenched such that it will serve as a mechanism for the maintenance of global order.

A third dimension which has fractured the cartography of suffering is global warming and the unanticipated environmental consequences of the world being vulnerable to the ferocious forces of nature which present future generations with pressing deliberations on sustainable energy, fuel usage, consumption, conservation, and the depletion of natural resources. The Anthropocene denotes the era of human impact on the environment, producing a subjectivity and a vulnerability to nature's prowess. As such, suffering can be unleashed through drastic weather 
patterns and natural disasters that reveal the powerlessness of mankind.

The West as a form of superior power in terms of technological wisdom, political might and ideological advancements through capitalism and democracy becomes a renewed figure of vulnerability where its constant battle to turn away from victimhood and intrinsic volatility reveals its reticence to be plucked from its superior role as the purveyor of compassion and pity. The engagement with suffering becomes an unsafe frontier when it becomes a part of Western identity. When suffering is firmly entrenched in the East, it is able to conceive itself through a magnanimous self-image of providing relief. It is less comfortable with victimhood associated with weakness and vulnerability mostly recognizable in the portrayals of the Other. The shifting cartography of suffering presents a challenge to the West's self-image and its commodification of the East as the theatre house of suffering. Despite this "new normality" of threat and disruption in the West, its sociological imagination of the East as the lesser Other remains a status quo. Terrorist threats and the rise of radicalized religion provide renewed forms of ammunition to thrust the spectacle of instability to the East through military interventions to reinsert and retain the geopolitics of power.

\section{Conclusion}

This paper argues that mediated suffering as a field of enquiry is in a state of crisis with its entrenched Orientalist paradigms and Eurocentrism. Its inherent weaknesses parallel those of communication and media studies which have been fragmented and sporadic in integrating postcolonial perspectives. The obsession with event analysis rather than the wider historical and social context of suffering produces an ahistoricity while infusing it with Western essentialism, dissecting humanity into a binary. The bias of the visual and modes of representation through technology, whether it be broadcast or new media platforms, produces more instabilities where the act of watching or consuming incessant images of suffering can remove us from real events while encoding us as audiences rather than fellow humans. Cultural modes of representation have the power to ignite affective communities but equally they can strip suffering from reality to offer them as commodities of consumption where they inscribe an aesthetic of violence and perverse pleasures rather than a communal politics of pity. With $9 / 11$ and the events which have ensued, the West has emerged as the new theatre house of suffering, with cities and buildings erupting without warning. This climate of the "new normal" is further destabilized by the movement of displaced people into the West and the formation of "migrant" camps which re-invoke the border politics of Westphalian sovereignty. In addition, the age of the Anthropocene signifies an increased vulnerability of humanity where suffering is unleashed through the ferocity of nature without distinguishing it through any specific cartography. Despite these wider processes which inflict increased trauma on the Western psyche and landscape, the scholarship of suffering remains shackled through its lens of enquiry, asserting the East as the retainer of suffering and hence elongating the Orientalist trajectory.

\section{Endnotes}

1. Garland (2005: 793) argues that "lynchers and their supporters used to describe and justify these events as criminal punishments, albeit summary, informal ones that were shaped by a white supremacist culture and a politics of racial domination. The penal character of these lynchings increased the probability that they would be tolerated by local (and even national) audiences and thus made them a strategic form of violence in struggles to maintain racial supremacy." 


\section{References}

Andermahr, S. (2015) Decolonising Trauma Studies: Trauma and Postcolonialism - Introduction. Humanities (4): 500-505.

Bennet, J., and Kennedy, R. (2003) Introduction in: Bennet J and Kennedy R (eds) World Memory: Personal Trajectories in Global Time. New York and London: Palgrave Macmillan, p.5.

Blondheim, M., and Liebes, T. (2002) Live Television's Disaster Marathon of September 11 and its Subversive Potential. Prometheus 20(3), pp.271-277

Boltanski, L. (1999) Distant Suffering: Morality, Media and Politics . Cambridge: Cambridge University Press.

Buchowski, Michal. 2006. "The Specter of Orientalism in Europe: From Exotic Other to Stigmatized Brother." Anthropological Quarterly 79 (3): 463-482.

Chouliaraki, L. (2006) The spectatorship of suffering. London: SAGE.

Chouliaraki, L. (2013) The ironic spectator: Solidarity in the age of post-humanitarianism. Cambridge: Polity Press.

Craps, S. (2013) Postcolonial Witnessing: Trauma Out of Bounds. Basingstoke: Palgrave Macmillan.

Haldrup, Michael, Lasse Koefoed, and Kristen Simonsen. 2006. "Practical Orientalism: Bodies, Everyday Life and the Construction of Otherness." Geography and Power, the Power of Geography 88 (2): 173-184

Hoijer, B. (2004) The Discourse of Global Compassion: the audience and media reporting of human suffering. Media, culture and society 26(4): 513-531.

Horstkotte, S. (2013) Transcending Trauma. Thomas Lehr's 9/11 Novel 'September. Fata Morgana'. Image and Narrative 14(1), Available at: http://www.imageandnarrative.be/index.php/imagenarrative/article/view/296 (accessed 25/01/2015).

Garland, D. (2005) Penal excess and surplus meaning: Public torture lynchings in twentieth-century America. Law \& Society Review , 39(4), 793-834.

Ghosh, A. (1994) The global reservation: notes toward an ethnography of international peacekeeping. Cultural Anthropology, 9(3), 412-422.

Ibrahim, Y. (2007) 9/11 as a new temporal phase for Islam. Contemporary Islam 1(1): 37-51.

Ibrahim, Y. (2009) Holocaust as the Visual Subject: The Problematics of Memory Making through Visual Culture. Nebula 6(4): 94-113.

Ibrahim, Y. (2010a) Distant suffering and postmodern subjectivity: The communal politics of pity. Nebula 7(1): 7.
Ibrahim, Y. (2010b) Bearing Witness through Technology: War and Visual Culture. Global Media Convergence and Cultural Transformation: Emerging Social Patterns and Characteristics: Emerging Social Patterns and Characteristics, 123.

Ibrahim, Y. (2011) Integrating the Postcolonial : The Missing Paradigm in Media Studies . Journal of the World Universities Forum 4(2): 35-42.

Ibrahim Y (2012) The Politics of Watching: Visuality and the New Media Economy. International Journal of E-Politics (IJEP) 3(1): 1-11.

Ibrahim, Y. (2018). The re-aestheticisation of poverty: blogging hunger in the age of austerity. Social Identities, 24(3), 364-379.

Kristeva, J. (1982) Powers of Horror: An Essay on Abjection (trans. Roudiez, LS). New York: Columbia UP.

Luckhurst, R. (2008) The Trauma Question. London: Routledge.

Mitchell, WJT. (2011) Cloning Terror: The War of Images, 9/11 to the Present. Chicago: University of Chicago Press.

Rothberg, M. (2008) Decolonizing Trauma Studies: A Response. Studies in the Novel 40: 224-34.

Said, EW. (1978) Orientalism. New York: Pantheon Books.

Silverstone, R. (2006) Media and Morality: On the Rise of the Mediapolis. Cambridge: Polity Press.

Tester, K. (2001) Compassion, Morality and the Media . Buckingham: Open University Press.

Todorova, Maria Nikolaeva. 1997. Imagining the Balkans. Oxford: Oxford University Press.

Visser, I. (2015) Decolonizing Trauma Theory: Retrospect and Prospects. Humanities 4: 250-265.

Wolff, Larry. 1994. Inventing Eastern Europe: The Map of Civilization on the Mind of the Enlightenment . Stanford, CA: Stanford University Press.

Wood, A. L. (2011). Lynching and spectacle: Witnessing racial violence in America, 1890-1940. University of North Carolina Press. 